
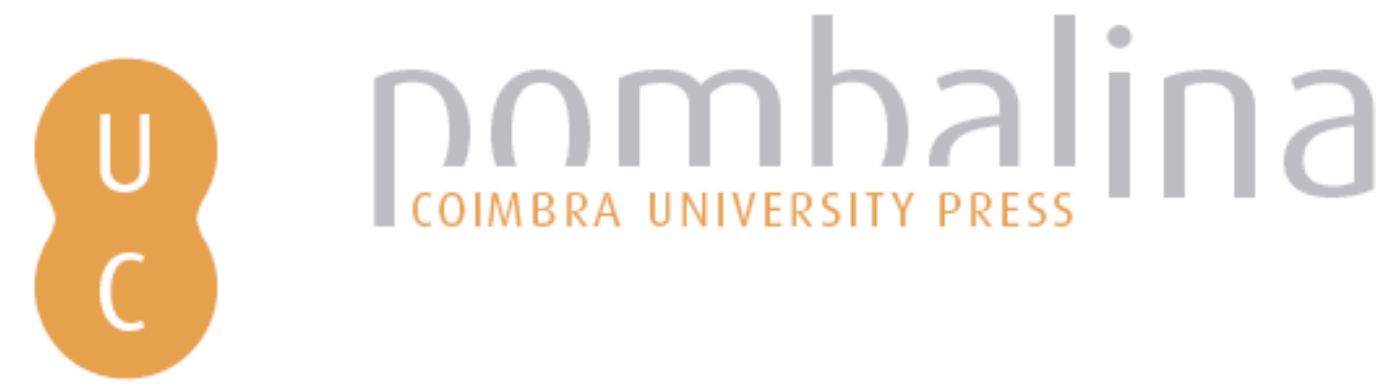

\title{
A educação cíbrida e as possibilidades para as docências no ensino superior: 0 POMAR em questão
}

Autor(es): $\quad$ Bruno, Adriana Rocha; Mattos, Ana Carolina Guedes

Publicado por: Imprensa da Universidade de Coimbra

URL

persistente: URI:http://hdl.handle.net/10316.2/47385

DOI: $\quad$ DOl:https://doi.org/10.14195/978-989-26-1716-9_9

Accessed : $\quad$ 26-Apr-2023 13:46:08

A navegação consulta e descarregamento dos títulos inseridos nas Bibliotecas Digitais UC Digitalis, UC Pombalina e UC Impactum, pressupõem a aceitação plena e sem reservas dos Termos e Condições de Uso destas Bibliotecas Digitais, disponíveis em https://digitalis.uc.pt/pt-pt/termos.

Conforme exposto nos referidos Termos e Condições de Uso, o descarregamento de títulos de acesso restrito requer uma licença válida de autorização devendo o utilizador aceder ao(s) documento(s) a partir de um endereço de IP da instituição detentora da supramencionada licença.

Ao utilizador é apenas permitido o descarregamento para uso pessoal, pelo que o emprego do(s) título(s) descarregado(s) para outro fim, designadamente comercial, carece de autorização do respetivo autor ou editor da obra.

Na medida em que todas as obras da UC Digitalis se encontram protegidas pelo Código do Direito de Autor e Direitos Conexos e demais legislação aplicável, toda a cópia, parcial ou total, deste documento, nos casos em que é legalmente admitida, deverá conter ou fazer-se acompanhar por este aviso.

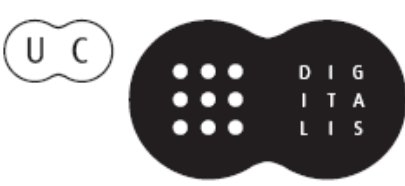



ADRIANA ROCHA BRUNO

Universidade Federal de Juiz de Fora-UFJF/Brasil

adriana.bruno@educacao.ufjf.br

ANA CAROLINA GUEDES MATTOS

Professora da Secretaria de Educação de Juiz de Fora-MG/Brasil

carolguededmat@gmail.com

\section{A E DUCAÇÃO CÍBRIDA EAS POSSIBILIDADES PARA AS DOCÊNCIAS NO ENSINO SUPERIOR: \\ O POMAR EM QUEST̃̃O ${ }^{1}$}

\section{Educação Aberta}

A cibercultura tem transformado as experiências, a produção e socialização de informações, os sentidos e significados de autoria, alterando as relações de emissão e recepção - que outrora centralizavam o saber nas mãos de poucos- ao conhecimento, tornando-o disponível a qualquer sujeito, em todo o mundo.

Neste cenário, a educação aberta passa a integrar os debates educacionais e já testemunhamos e produzimos ações viabilizadas por espaços interativos online. Os Percursos Formativos Abertos na Cibercultura, fruto de uma das investigações realizadas pelo Grupo de Pesquisa Aprendizagem em Rede GRUPAR-UFJF, notadamente com a pesquisa "Formação docente no ensino superior em tempos de cibercultura: multiplicidade, coaprendizagem e educação online", financiada pela FAPEMIG, iniciada em 2013 e finalizada em 2015, serão abordados neste texto.

\footnotetext{
1 Artigo produzido a partir da publicação para o Eixo Temático 11 - Educação a distância/ Educação online/Métodos e processos pedagógicos do IX Simpósio Nacional da ABCiber - dez/2016. - http://abciber2016.com/wp-content/uploads/2016/trabalhos/percursos_formativos_abertos_na_cibercultura_adriana_rocha_bruno.pdf
} 
O objetivo principal deste artigo é promover reflexões que nos ajudem a compreender a Cultura contemporânea, seus desafios e possibilidades na área da educação e debater, dentre diversas alternativas, a proposta de Percursos Online Múltiplos Abertos e Rizomáticos (POMAR) como potenciais para a aprendizagem, num mundo cíbrido. A ideia dos POMAR, criados por Bruno (2014) e o Grupo de Pesquisa Aprendizagem em Rede (GRUPAR), é produzir ambientes de aprendizagem que promovam experiências autônomas, singulares, coletivas e colaborativas entre os sujeitos aprendentes. Para entender estes percursos serão também evidenciadas as noções multirreferenciais de cibercultura, de Educação Aberta e cíbrida, Redes rizomáticas e plásticas como composições que fundamentam esta proposta e sustentam a cocriação destes percursos abertos.

O GRUPAR, fundado em 2009, é coordenado pela Prof. ${ }^{a}$. Dr. ${ }^{a}$. Adriana Rocha Bruno, da Faculdade de Educação da Universidade Federal de Juiz de Fora (Minas Gerais-Brasil). Esta cidade montanhosa, com aproximadamente 500 mil habitantes, fica na região sudeste do Brasil e é próxima do Rio de Janeiro $(180 \mathrm{~km})$. A referida professora, e também coautora deste artigo, é docente e pesquisadora em dois programas de pós graduação e da graduação em Pedagogia, coordena o Curso de Especialização Midias na Educação e é vice-coordenadora do Curso de Pedagogia da UFJF. Estuda e pesquisa há quase vinte anos a aprendizagem e os processos de docência em meio a Cultura Digital. Para tanto, integra estudos dos diversos campos científicos como neurociências, comunicação, psicologia, filosofia e educação, tendo como principal base metodológica a multirreferencialidade (Ardoino, 1998). Desenvolveu temas de estudo e pesquisa que hoje fundamentam suas ideias e práticas, como: Linguagem emocional (Bruno, 2002), mediação partilhada (Bruno, 2007, 2012), redes rizomáticas (Bruno, 2010), aprendizagem integradora (Bruno, 2007) e os percursos online múltiplos, abertos e rizomáticos (Bruno e Schuchter, 2014, Bruno, 2016).

O GRUPAR possui três linhas de pesquisa: (a) educação online; (b) tecnologias digitais da informação e comunicação - TDIC - em educação; e (c) docências contemporâneas. Os membros do grupo tem a diversidade como uma marca particular: são graduandos, mestrandos, mestres, doutorandos, doutores, professores da Educação Básica e Superior, das redes de ensino 
pública e privada. Tal contexto permite produzir um diálogo profícuo e trocas epistemológicas entre a universidade e o cotidiano educacional, tecendo uma rede integrada com a educação básica. As ações do grupo se dividem em dois momentos presenciais: estudos (encontros quinzenais) e pesquisas (encontros semanais), em que há contribuição e participação efetiva dos membros-pesquisadores. Há ainda espaços dialógicos online em que são utilizados ambientes fechados: o Moodle (em menor frequência atualmente), o Facebook e o Whatsapp, e recentemente criamos um outro espaço aberto, mas que é um protótipo ainda, por meio do POMAR, que será apresentado adiante.

Educação Aberta é um movimento integra a abertura e o acesso da Educação a todos (Inuzuka e Duarte, 2012). Ainda que esteja ocorrendo há décadas e de diversas formas, um dos marcos mais recentes deste tipo de educação e que converge com a cultura digital está na Declaração da Cidade do Cabo, de 2007 , que reafirma a crença na solidariedade da partilha de boas ideias entre educadores e a cultura da internet fundada na colaboração e interação, tendo como premissa também a liberdade no uso, aperfeiçoamento e reuso de recursos educacionais.

Uma das bases da Educação Aberta está, para nós, associada à Educação humanista de Rogers (1997), que propõe uma educação descentralizadora, cujo processo de aprendizagem seja protagonizado pelo aprendiz ao trilhar seu trajeto como sujeito ativo e responsável pela sua aprendizagem. Este tipo de abordagem forja a potencialidade de se produzir processos formativos abertos, participativos e colaborativos na medida em que os sujeitos implicados na aprendizagem assumem-se como corresponsáveis pelos percursos cocriados.

De acordo com Santos (2011), na década de 1970 a Educação aberta começa a ser discutida pelas Universidades Abertas do período (a partir da década de 1970). Conforme as reflexões de Santos (2012), o conceito de Educação Aberta vai se adaptando à nova realidade da sociedade na qual vivemos. Para a estudiosa,

Normalmente, refere-se a um conjunto de práticas educativas. É utilizado na educação infantil e de adultos; formal e informal; presencial ou a distância. Termo contemporaneamente utilizado pelo movimento de recursos educacionais abertos, mas não exclusivo ao mesmo. (Santos, 2012) 
Pensando na década do surgimento dessas práticas educativas, mencionadas por Santos, podemos fazer uma relação com os estudos de Otto Peters sobre a Educação a Distância. Peters (2004) considera a década de 1970 como o início da nova era da educação a distância, na qual o uso de eletrônicos analógicos (rádio e televisão) e, mais tarde, dos vídeos e das fitas cassete contribuíram consideravelmente para o acesso ao conhecimento. Segundo Peters, as novas características dessa educação tinham como características o:

(...) considerável progresso na criação e no acesso à educação superior para grupos maiores de adultos, experimentação pedagógica, a aplicação de cada vez maior de tecnologias educacionais, a introdução e a manutenção de aprendizado aberto e permanente e o início da educação superior em massa. (Peters, 2004, p. 32)

As ponderações de Peters sinalizam para a importância do movimento da Educação aberta como possibilidade de ensino e de aprendizagem que utiliza a "abertura" das mídias, que existem antes mesmo da criação e da expansão da web. Por conseguinte, consideramos que vivemos em uma Era digital (Santaella, 2004), e a Educação Aberta passa a se configurar como um movimento ligado a essa era.

A ideia de cibercultura, notadamente divulgada pelo estudioso Pierre Lévy (1999), defende que a sociedade está inserida nesse novo ambiente complexo e multifuncional, um espaço de possibilidades para a comunicação, definido como ciberespaço. O ciberespaço potencializa diversas maneiras o indivíduo para se relacionar e se interligar aos seus pares, realidade esta que representa uma das características da pós-modernidade. Lemos (2004) reforça o uso do ciberespaço pelo humano, em que o usuário "solta as amarras e desenvolve-se de forma onipresente, fazendo com que não seja mais o usuário que se desloca até a rede, mas a rede que passa a envolver os usuários e os objetos numa conexão generalizada" (2004, p. 1).

Compreendemos que a cibercultura promove uma Educação integrada e que Schuchter (2017) denomina de cíbrida. As Educações Cíbridas como aquelas que integram, no mesmo espaço tempo: tecnologias digitais e analógicas, ideias, pessoas, recursos, ambientes online e presenciais, dispositivos e artefatos, enfim, educações que ressignificam e redimensionam os ambientes, 
cocriando entrelugares para os processos de ensino e de aprendizagem dos sujeitos contemporâneos. Distinguem-se de híbridas pois estas alternam ora online ora presenciais, mas não necessariamente integram, fundem, como as cíbridas. Optou-se, portanto, pelo uso do termo cíbrido neste artigo por percebemos ainda que o híbrido pode oferecer certas confusões. Explicamos: A profa Adriana Bruno, numa de suas apresentações, proferiu palestra em que o termo Educação Híbrida foi utilizado. No público um grupo de pessoas da área da saúde e biologia chamou a atenção para o significado de híbrido no campo da saúde: organismos formados pelo cruzamento de espécies diferentes resultando em seres inférteis. Destarte, o uso de Educação híbrida por exemplo pode indicar, a depender do público, infertilidade, o que difere em absoluto da ideia desejada.

Santos (2011) destaca algumas características da Educação aberta e da liberdade do estudante no acesso ao conhecimento pretendido. De acordo com as ponderações da estudiosa:

I) o estudante tem a liberdade de escolher o lugar no qual irá estudar (casa, trabalho ou instituição de ensino); II) pode estudar por módulos, créditos, ou qualquer forma que auxiliará o estilo de vida do estudante; III) pode fazer uso da autoinstrução a partir de uma certificação opcional; IV) pode obter isenção de taxas de matrícula, ou mensalidade para a realização do curso desejado; V) pode obter isenção de vestibular e de qualificações prévias; VI) pode fazer uso de REA na educação formal ou informal (Santos, 2011, p. 74).

Ao pensarmos na Educação aberta, é importante considerarmos as condições materiais que influenciam diretamente as maneiras como ela acontece, ou seja, há que se considerar: as instituições, os sistemas e os recursos disponíveis. Por isso, para que esse movimento aconteça, é importante que as práticas culturais sejam abertas, híbridas, compartilhadas e colaborativas. Em seus estudos, Santos (2011) destaca a contribuição das Universidades Abertas como potencializadoras deste tipo de educação. O exemplo mais conhecido de Universidade Aberta é a Open University do Reino Unido, que oferece ao cursista o estudo por módulos, materiais e a certificação obtida por créditos. 
Convergentes com a Educação Aberta, os REA (Recursos Educacionais Abertos) como estratégias/práticas potencializam o acesso ao conteúdo e a possibilidade de reutilização, alteração do material, conforme a demanda dos cursistas, ou até mesmo plataformas abertas para o compartilhamento de materiais. Para Santos (2011, p 12), "Percebemos que, ao longo das décadas, uma das características principais da educação aberta de crianças e adultos é um processo de ensino/aprendizagem centrado no estudante, com apoio contínuo à aprendizagem.”

A liberdade de escolha do que irá aprender e da organização dos conteúdos que devem ser aprendidos são outras ponderações da Educação aberta. Percebemos similaridades com o que Mizukami (1986) destaca no Humanismo: "Ao experienciar o homem conhece". Logo, a educação deverá criar condições para a aprendizagem, levando à valorização progressiva de autonomia. Essa é uma análise inicial das características comuns nessas abordagens.

As possibilidades atuais da Educação Aberta estão materializadas de diversas formas e as redes sociais online e os Recursos Educacionais Abertos (REA) se constituem, respectivamente, como espaços e recursos potentes para este tipo de educação. De certo modo, os Massive Open Online Courses (MOOC) também emergiram com tal perspectiva, considerando o conexionismo que os suporta. Tal discussão oferece um campo fértil para as relações entre a tecnologia digital e a educação; duas áreas que impactam o ser humano contemporâneo e alteram suas relações sociais, políticas e culturais.

Estudos desenvolvidos pelo GRUPAR, que incluiu também análises críticas acerca dos MOOC, por meio da pesquisa de Mattos (2015), emergiu a questão: Como produzir ambientes de aprendizagem que integrem a Educação de abertura e os REA, de modo a promover aprendizagens de adultos mais autônoma e críticas, e que constituam redes rizomáticas?

\section{Noções e produções}

O contato com os estudos de Gilles Deleuze e Felix Guattari, no Grupo de Pesquisa Aprendizagem em Rede (GRUPAR), despertou o nosso olhar para algumas acepções sobre o mundo e o pensamento contemporâneos. Do 
mesmo modo, é notória a relevância e influência que exerceram no percurso de produção desta dissertação de Mattos (2015) e o lugar de excelência que alguns conceitos ocupam no desenvolvimento das discussões ora apresentadas. As ideias de multiplicidades, de devir, de plano de imanência e de rizoma, trazidos por tais estudos, foram imprescindíveis para a compreensão dos acontecimentos da noção de redes e seus desdobramentos.

As multiplicidades, em Deleuze e Guattari (1995), são peças que compõem “objetos parciais”, são realidades que não desconsideram, nem perdem o todo; dessa maneira podemos atingir as condições da experiência "real". "A multiplicidade não deve designar uma combinação de múltiplo e de um, mas, ao contrário, uma organização própria do múltiplo enquanto tal, que não tem necessidade alguma da unidade para formar um sistema" (Deleuze, 1998, p. 236). Ao pensarmos na multiplicidade, ponderamos que Deleuze e Guattari anunciam a composição de dimensões que se englobam e recapturam umas às outras em graus distintos aos anteriores. Multiplicidades são realidades, são acontecimentos que podem ocorrer ao mesmo tempo ou em tempo distintos, mas um fato não elimina a importância de todas as realidades.

Pensando nas multiplicidades, os rizomas as constituem, nas palavras de Deleuze e Guattari (1995, p. 13): "subtrair o único da multiplicidade a ser constituída; escrever a n-1. Tal sistema poderia ser chamado rizoma." O rizoma é uma pseudoraiz que não possui um formato comum às outras raízes: cada ramificação pode ser diferente e crescer por caminhos distintos. Ele não é uno, nem múltiplo, mas feito de dimensões, de direções que se alteram.

Pensando na rede e nos desdobramentos desses cursos na realidade brasileira, aceitamos as provocações de Deleuze e Guattari (1997). Deleuze é chamado de "filósofo das multiplicidades" por Gallo (2008, p. 29). Dessa maneira, entendemos que suas proposições podem inspirar as análises e as interpretações desenvolvidas. A investigação pode se constituir no plano de imanência, campo de produção de ideias e espaço infinito em que não há afirmações como verdades e achados definitivos. Gallo revela que "o plano de imanência é essencialmente um campo onde se produzem, circulam e se entrechocam os conceitos" (Gallo, 2008, p. 44).

Compreendemos o movimento da investigação como um encontro entre o que suspeitamos, o que encontramos e o que reelaboramos. Sendo assim, a 
posição ativa do pesquisador junto aos sujeitos é fator relevante nessa abordagem, potencializando um campo de múltiplas possibilidades e entrechoques de conceitos, conforme menciona Deleuze e Guattari (1995).

Convergente e em complemento a tais ideias, Bruno (2010) fala de uma educação que é plástica, flexível e rizomática, que não possui um dentro e um fora, mas um dentrofora, dobras, rotas, trajetos, travessias (in)visíveis.

\section{POMAR: questionamentos na Educação Aberta}

Integrar a educação aberta e os REA implicou no movimento de materializar, por parte do nosso grupo de pesquisa, de colocar em prática nossas ideias: produzir redes rizomáticas, ou seja, criar "espaço para a invenção do pensamento, individual e coletivo, um espaço em que seja possível fomentar a formação de redes com hastes e rotas de fuga, a ampliação de redes e o questionamento das redes" (BRUNO, 2010, p. 186).

A proposta de Percursos Formativos Abertos na Cibercultura se desenvolve em meio a e é promovido por um cenário mundial plural, em que múltiplas tecnologias e ideias convergentes se integram a estudos e conceitos produzidos no cerne das investigações do GRUPAR.

O POMAR está ancorado nas concepções de Educação Aberta, de Recursos Educacionais Abertos, de Aprendizagem Experiencial, de Mediação Partilhada e de Redes Rizomáticas. São ambientes colaborativos abertos, de acesso, produção e socialização de informações e de conhecimentos. Visam à participação ilimitada e livre das pessoas que se abrem a aprendizagem colaborativa e autônoma - por meio da interação sujeito-web.

Nos Percursos os interessados criam seus próprios e singulares trajetos, caminhos. Pelas potencialidades dos ambientes Online tudo e todos estão 'em conexão', e podem-devem cocriar redes. Tais relações interativas são Múltiplas, no sentido da multiplicidade deleuziana, que possibilita níveis de intensidade e aprofundamento das temáticas/conteúdos abordados para/por/com qualquer pessoa que tenha interesse nos temas produzidos, bem como na cocriação de outras temáticas interligadas. Por fim, são Abertos e Rizomáticos em sua convergência com os pressupostos da Educação Aberta e de REA, pois 
os POMAR não possuem começo, meio e fim já que cada um pode acessar o que quiser e como quiser. Tal como os rizomas não são estruturados, não são fixos e se retroalimentando da própria rede.

Dar acesso e múltiplas possibilidades aos participantes nos levou a não realizar cursos, pois pressupõe uma estrutura determinada de conteúdos, de currículo e de tempo, com início e término. A proposta do POMAR é que todos produzam seus Percursos, que sejam coautores (os propositores e os cursistas), e cada cursista navegue pelo espaço da maneira que achar mais potente e de modo não linear, de acordo com os seus interesses sobre os temas disponíveis, ou a temática do POMAR que escolher aprender ou aprofundar. Mais do que isso, o POMAR se faz por meio da retroalimentação dos sujeitos que de participantes passam a ser agentes e coautores daqueles espaços.

Diante das reflexões e leituras sobre as questões da Educação aberta e suas possibilidades, resolvemos elaborar uma proposta que fosse ao encontro das interpretações e análises realizadas em nossas pesquisas. Foi criado um protótipo, um ambiente online, um piloto, que permitisse abertura máxima para quaisquer interessados nos temas disponibilizados. Foi escolhido um tema específico que integra nossas ações e pesquisas: as docências. $\mathrm{O}$ primeiro POMAR (Percursos Online Múltiplos Abertos e Rizomáticos) criado foi o POMAR: Docências.

A imagem a seguir ilustra a primeira experiência com o POMAR. 


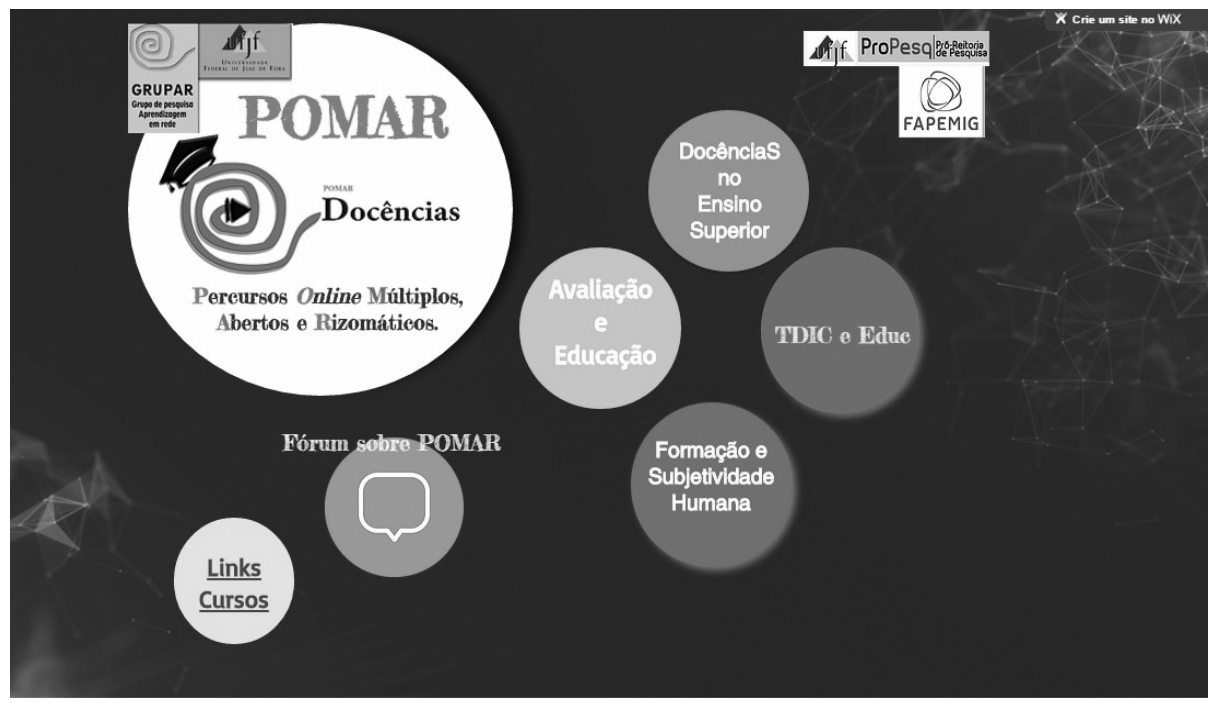

IMAGEM 1: Site do POMAR - Docências, do GRUPAR/UFJF

Os botões-links das temáticas relacionadas às Docências estão dispostos sem uma ordem ou posição linear. Do ponto de vista da navegabilidade e da abertura, o cursista fica livre para acessar todos os temas ou mesmo se aprofundar em um único, dos quatro disponíveis. É oportuno argumentar que a ideia-proposta do POMAR deve ser desenvolvida por qualquer profissional ou estudante e para qualquer temática, pois tais ambientes para percursos não estão relacionados, especificamente, à educação. Logo, poderemos ter POMAR em diversas áreas, como de engenharia, de biomedicina e de administração, dentre outros. Assim, como destaca Bruno (2016), o POMAR é um espaço aberto para (trans)formação coletiva, autônoma e colaborativa de online.

Os POMAR criam espaços formativos online, digitais e em rede; abertos para qualquer pessoa que tenha interesse nos temas disponíveis; múltiplos, no sentido de possibilitar níveis diversos de intensidade e aprofundamento das temáticas/conteúdos tratados; nele, os interessados criam seus trajetos, seus caminhos, suas rotas e travessias da forma que desejarem. (BRUNO, 2016)

Diferente dos MOOC, por sua abertura total e pela necessidade efetiva de autonomia dos usuários, estes percursos abertos, não se enquadram na ideia de massividade, ainda que esta possa ser compreendida como profundidade, pois as distorções que este conceito apresenta nos estudos da área da comu- 
nicação com as mídias massivas, é inevitável, e implica em cursos em massa. Portanto, um POMAR não é um tipo de MOOC, pois não é curso, mas Percurso criado e alimentado pelas redes de participantes e mais: há necessidade de se projetar espaços para debates, de modo que todos possam propor e mediar questões e discussões.

Cada temática do POMAR piloto criado tem como intenção a problematização, a cocriação e a colaboração, disponibilizando um espaço de debate-discussão, de crítica e de constante construção. Dentro da temática TDIC e Educação, por exemplo, o participante poderá acessar textos, vídeos, REA e fórum de discussão. Este espaço de discussão foi denominado "Provocações" e é um espaço essencial num POMAR pois é lá que os debates, mediações pelos usuários e emergências aparecem.

Por ser uma obra aberta, o POMAR está em constante construção e se alimenta dos interessados que acessam o ambiente e contribuem com debates, questões e também materiais ou temas e subtemas, se desejarem.

\section{Considerações Finais}

Para que a Educação Aberta 'aconteça', a incorporação de recursos educacionais abertos passa a ser parte desse trajeto. Produzir e socializar, colaborativamente, desdobrar, dar-ter acesso, remixar, valorizar as múltiplas produções de conhecimento existentes e incorporá-las ao consumido e ao produzido é ser um educador/aprendiz aberto. Não se trata de fazer uso dos REA, mas de pensar e agir de modo que a abertura seja o sentido do sujeito.

Em contextos educativos, concepções de aprendizagem estão sempre subjacentes às práticas neles desenvolvidas e, a educação aberta tem sido associada ao conectivismo, termo cunhado por George Siemens e Stephen Downes (Siemens, 2012), que está baseado nas seguintes premissas: a autonomia, a diversidade, o grau de abertura, a conectividade e a interatividade.

Pensando na cibercultura, e mais especificamente na web, podemos inferir novas formas de ensino e de aprendizagem por meio da partilha, da construção colaborativa e da abertura no acesso, assim como na proposta apresentada pela ideia de POMAR. 
O incentivo e a disseminação dessas ideias e práticas implicam na reflexão e na prática libertadora e democrática de se fazer educação, bem como tensionar os debates acerca de questões como abertura e direito autoral; políticas públicas e de fomento à tecnologia para promoção de movimentos dentro e fora do campo educacional.

\section{Referências bibliográficas}

AMIEL, T.; OREY, M.; WEST, R. (2010) Recursos Educacionais Abertos (REA): modelos para localização e adaptação. ETD-Educação Temática Digital, v. 12, n. mar., p. 112-125. Disponível em: < http://www.fae.unicamp.br/revista/index.php/etd/article/view/2284 >. Acesso em: 08/10/ 2017.

AMIEL, T. (2011). Recursos Educacionais Abertos (REA): um caderno para professores. Campinas (SP): Educação Aberta. Disponível em <www.educacaoaberta.org/>. Acesso em 10/05/2017.

BRUNO, A. R. (2007). Aprendizagem do adulto educador: estratégias para uma didática on-line. Tese defendida no Programa de Pós-Graduação em Educação: Currículo. 257p. Pontifícia Universidade Católica de São Paulo. Disponível em https://sapien tia.pucsp.br/bitstream/handle/9974/1/Adriana\%20Rocha\%20Bruno.pdf Acesso em $29 / 10 / 2017$.

BRUNO, A. R. (2010). Travessias invisíveis: plasticidade, diferença e aprendizagem em redes rizomáticas de formação de adultos educadores nos ambientes on-line. In. XV Endipe Didática e prática de ensino: convergências e tensões no campo da formação e do trabalho docente, Belo Horizonte/MG: Autêntica. v.2. p.171-196. Disponível em: <http://www.fae.ufmg.br/endipe/livros/Livro_3.PDF>. Acesso em $10 / 10 / 2017$.

BRUNO, A. R. (2016). Espaços de coproduções para as docências e aprendências: uma análise das bases teóricas e metodológicas da experiência POMAR. In: Mill, D, Reali, A. Educação a distância, qualidade e convergências: sujeitos, conhecimentos, práticas e tecnologias.1 ed.São Carlos-SP: EDUFSCAR. v.1, p. 193-204.

BRUNO, A. R., PESCE, L. (2012). Mediação partilhada, dialogia digital e letramentos: contribuições para a docência na contemporaneidade. Atos de Pesquisa em Educação - PPGE/ME FURB ISSN 1809-0354 v. 7, n. 3, p. 683-706, set./dez. 
DELEuZE, G. (1998). Diferença e repetição. São Paulo: Graal.

DELEUZE, G., \& GUATTARI, F. (1995). Mil Platôs: capitalismo e esquizofrenia. V. 1. Trad. Neto, A. G., \& Costa, C. P. São Paulo: Ed. 34 (Coleção Trans).

Deleuze, G. (2011). Lógica do sentido. São Paulo: Perspectiva.

GALLO, Silvio. (2008). Deleuze \& a educação. 2. ed. Belo Horizonte: Autêntica.

INUZUKA, M. A., DUARTE, R. T. (2012). Produção de REA apoiada por MOOC. In:<http:// www.artigos.livrorea.net.br/2012/05/producao-de-rea-apoiada-por-mooc/>. Acesso em 10/10/2017.

LEMOS, A. (2004). Cibercultura e mobilidade: a era da conexão. Razón Y Palabra. n.41, out/nov.

LÉVY, P. (1999). Cibercultura. Tradução: Carlos Irineu. São Paulo: Ed. 34.

MATTAR, J. (2013). Aprendizagem em ambientes virtuais: teorias, conectivismo e MOOCs. Teccogs. n. 7, jan.-jun. Disponível em: http://www.pucsp.br/pos/tidd/tec cogs/artigos/2013/edicao_7/2-aprendizagem_em_ambientes_virtuais-joao_mattar. pdf. Acesso em 18/05/2017.

MATTOS, A. C. G. (2015). MOOC: uma análise das produções nacionais e internacionais. Dissertação de mestrado. Programa de Pós-Graduação em Educação da UFJF.

MIZUKAMI, M. G. N. (1986). Ensino: as abordagens do processo. [S.1.]: EPU.

PRETTO. N. L. (2012). Professores-autores em rede. In: Santana, B.; Rossini, C.; Pretto, N. L. Recursos Educacionais Abertos: práticas colaborativas e políticas públicas. São Paulo/Salvador: Casa da Cultura Digital/EDUFBA. (p. 91 - 108). Disponível em http://www.artigos.livrorea.net.br/2012/05/professores-autores-em-rede/. Acesso em 17/09/2017.

ROGERS, C. R.(1997). Tornar-se pessoa. Trad. Ferreira, M. J. C. 5 ed. São Paulo: Martins Fontes.

SANTAELlA, L. (2004). Culturas e arte do pós-humano: da cultura das mídias à cibercultura. CASTRO, Valdir José de (coord). 2. ed. São Paulo: Paulus.

SANTOS, A. I. (2011). Open Educational Resources in Brazil: State-of-the-art, Challenges and Prospects for Development and Innovation. Moscow: UNESCO - Institute for Information Technologies in Education. 2011, p. 76. Disponível em http://unesdoc.unesco.org/images/0021/002149/214975e.pdf . Acesso em 27/08/2017.

SANTOS, A. I. (2012). Educação aberta: histórico, práticas e o contexto dos recursos educacionais abertos. In: SANTANA, B.; ROSSINI, C.; PRETTO, N. L. Recursos Educacionais Abertos: práticas colaborativas e políticas públicas (p 71 - 89). São Paulo/ 
Salvador: Casa da Cultura Digital/EDUFBA. Disponível em http://www.artigos.livrorea.net.br/wp-content/uploads/2012/05/REA-santos.pdf. Acesso em 20/09/2017. SCHUCHTER, L. H. (2017). ESCOLA.EDU: as políticas públicas de formação docente para o uso das tecnologias digitais na rede municipal de ensino de Juiz de Fora. (Tese de doutorado). Programa de Pós Graduação em Educação da Universidade Federal de Juiz de Fora-MG/Brasil.

SIEMENS, G. (2012). MOOCs are really a platform. Elearnspace, July 25. 